TI 2011-106/3

Tinbergen Institute Discussion Paper

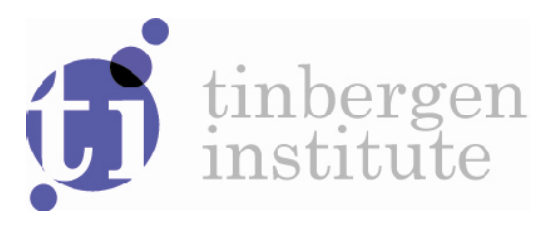

\title{
Analysis of Regional Innovation Performance in Portugal - Results from an External Logistic Biplot Method
}

Purificación Vicente Galindo'

Teresa de Noronha Vaz²

Peter Nijkamp

Eric de Noronha Vaz

1 University of Salamanca, Spain, and CIEO, University of the Algarve, Faro, Portugal;

2 CIEO, University of the Algarve, Faro, Portugal;

3 VU University Amsterdam, and Tinbergen Institute;

4 Institute of Statistics and Information Management, Universidade Nova de Lisboa, and CIEO, University of the Algarve, Faro, Portugal. 
Tinbergen Institute is the graduate school and research institute in economics of Erasmus University Rotterdam, the University of Amsterdam and VU University Amsterdam.

More TI discussion papers can be downloaded at http://www.tinbergen.nl

Tinbergen Institute has two locations:

Tinbergen Institute Amsterdam

Gustav Mahlerplein 117

1082 MS Amsterdam

The Netherlands

Tel.: +31(0)205251600

Tinbergen Institute Rotterdam

Burg. Oudlaan 50

3062 PA Rotterdam

The Netherlands

Tel.: +31(0)10 4088900

Fax: $+31(0) 104089031$

Duisenberg school of finance is a collaboration of the Dutch financial sector and universities, with the ambition to support innovative research and offer top quality academic education in core areas of finance.

DSF research papers can be downloaded at: http://www.dsf.nl/

Duisenberg school of finance

Gustav Mahlerplein 117

1082 MS Amsterdam

The Netherlands

Tel.: +31(0)20 5258579 


\title{
ANALYSIS OF REGIONAL INNOVATION PERFORMANCE IN PORTUGAL - RESULTS FROM AN EXTERNAL LOGISTIC BIPLOT METHOD
}

\author{
Purificación Vicente Galindo ${ }^{1}$ \\ Teresa de Noronha $\mathrm{Vaz}^{2}$ \\ Peter Nijkamp ${ }^{3}$ \\ Eric de Noronha $\mathrm{Vaz}^{4}$
}

\begin{abstract}
Portuguese strategic choices regarding innovation and R\&D policy have, over the past two decades, produced various positive achievements, in which the regions of Lisbon and Algarve have taken the lead, and are the only ones in the country to converge towards the European average growth rate. Regarding the other Portuguese regions despite significant national growth rates in the 1990s as well as a successful attempt to cope with the EMU -, these are lagging behind the EU average with respect to gross production, investment or employment generation. Meanwhile, one of the greatest public policy efforts was to diffuse much of the European funds across the entrepreneurial sector. After a long pathway, it is now timely to evaluate the firms' contribution to national and regional growth, their obstacles and impacts.

For the purpose of this paper, innovation is used here as a major contributor to the policy evaluation process referred to above. Our investigation aims to explain the present performance of Portuguese firms located throughout the country and to explore those innovation determinants that have a region-specific connotation. To provide a thorough investigation, our analysis defines, on a regional basis, a set of firms' behavioural patterns regarding innovation.

In our modelling, we employ a new methodology, viz. the External Logistic Biplot method, which is applied to an extensive sample of innovative institutions in Portugal. Variables such as 'Promoting knowledge', 'Management skills', 'Promoting R\&D', 'Knowledge transfer', 'Promoting partnership \& cooperation', and 'Orientation of public measures' have been identified as crucial determinants in earlier studies and are now used to describe regional institutional profiles. Such profiles exhibit a great variety in the way they combine these determinants to promote regional innovation. The creation of a gradient of capacity to dynamically innovate associated with each firm makes it possible to analyse the innovation gradient of each region in Portugal. Our paper presents and systematically investigates these findings and then reaches some policy conclusions.
\end{abstract}

Key Words: Innovation, Firms' Performance, Regional Innovation Systems, Principal Coordinates Analysis, External Logistic Biplot, Voronoi Diagram, Dissimilarity Matrix

Pn395pgmtv

\footnotetext{
${ }^{1}$ Department of Statistics, University of Salamanca, Spain, and CIEO - Research Centre for Spatial and Organizational Dynamics, University of the Algarve, Faro, Portugal.

${ }^{2}$ Corresponding author: mtvaz@ualg.pt, Faculty of Economics and CIEO - Research Centre for Spatial and Organizational Dynamics, University of the Algarve, Faro, Portugal.

${ }^{3}$ Faculty of Economics and Business Administration, VU University, Amsterdam, The Netherlands.

${ }^{4}$ Institute of Statistics and Information Management, Universidade Nova de Lisboa and CIEO - Research

Centre for Spatial and Organizational Dynamics, University of the Algarve, Faro, Portugal.
} 


\section{Introduction}

There are sharp regional differences in Portugal. This phenomenon, common to most of the southern European countries, has been extensively studied from the perspective of regional science (Nijkamp, 2009). In the Portuguese case, most of the socio-economic indicators demonstrate that economic activities are becoming more concentrated in the northern and western areas (OECD, 2008) as a result of various structural factors. Probable impediments on economic development in the rest of the country include those relating to knowledge flows, referred to as knowledge filters in the current literature (Acs et al., 2004; Audretsch et al., 2006; Stough and Nijkamp, 2009), while there is also a lack of a clear focus on regional innovation systems, as pointed out by OECD (2008).

Fagerberg (1987) proved that a long-lasting technology gap could explain why growth rates differ among countries and regions. Notwithstanding the theoretical justification, so far, most of the detected empirical problems have remained unsolved. In general, the causes for this heterogeneous behaviour and the cyclic nature of disadvantages in the European southern peripheries have attracted the attention of many researchers (Hall and Wee, 1995), as well as the attention of interested policy makers (Landabaso, 1997). One reason for this is that the role of firms, in particular the smallest ones, in the dynamics of regional growth has not yet been sufficiently investigated. Despite the significant efforts made by the Italian School founded by the GREMI group (Camagni, 1991, 1995a, 1995b; Camagni and Haillot, 1999) and, later on, by many other northern European researchers, such as Asheim and Isaksen (2003), still not much is certain regarding the direct contribution of individual firms or even industrial clusters to foster regional growth, the analysis of spillover effects being crucial in this regard (Kaiser, 2002; Fischer, 2006).

Because the area of influence of each firm varies depending on its nature, firms' environments cannot be defined easily from a geographical perspective (Kalandaridis et al., 1995). However, for a rough definition, the firm's environment should be associated, firstly, with those agents involved in the historical path-dependent development of skills (Teigland and Schenkel, 2006). Secondly, it should also be established on the basis of the many strategic interactions occurring such as those connections that form productive links within the firm's industrial structure: the cluster, which may be (or may be not) located in the near proximity of the firm. Finally, the firm's environment is highly influenced by the nature of the involved public institutions and their regulations - they may facilitate or aggravate the quality of all interactions.

In this context, much can be argued if the strategic decision of firms is mainly internally or externally driven, considering that their capabilities to confront uncertainty is frequently oriented to the future need of resources and clients. Langlois and 
Robertson (1995) developed the idea that "questions of firm strategy and firm boundaries are closely related".

These strategic choices will be usually solved by firms using market solutions, but through which decision-making process? As assessed by Freel (1998), not much is understood on how technologically innovative firms grow, learn or adapt to transformations in their environments. In his presentation of a conceptual framework of evolutionary strategic learning, he analyses how innovative small firms accumulate knowledge through learning, acting as a process of uncertainty-reduction. These processes do not necessarily work to get economies of scale, but improve the better understanding of cost composition, thereby helping to find out the better decision. Acquisition of knowledge sometimes involves the entrepreneur in a capability of strategic learning viewed as an opportunity to access economies of scope rather than scale. Thus, the routines of innovative firms are different from those of their noninnovative counterparts: examples are the different forms of human capital on pre-start knowledge about costs, a greater reliance on external networks for advice and support.

Empirical studies often underline the role of the environment, defined as the local context into which enterprises develop their activities (Keeble, 1997 and Freel, 1998). Others emphasize the fact that this unique link is indeed a bi-univocal flow (Vaz et al., 2004).

Literature advanced demonstrating that organizational learning and institutional networking work together in the behaviour of innovative firms (Fagerberg, 2003), in spite of the fact that some observations proved a reluctance of firms to cooperate locally (Wig and Wood, 1997). As a possible solution some studies point out for the need of specific networks for technological learning through external sources. There are interfaces which help them to combine sources of technical know-how, information and relations (Stough et al., 2007). The firms are probably organized in institutional local networks, whose help comes from their capacity to create cohesion or a favourable context for innovation; this cohesion may be represented as some sort of proximity, more cultural and social than geographical (Belotti, 1999).

Hence, the firm's environment appears to be a critical factor for the development or atrophy of the enterprise in many reported studies. For example, a negative effect of the SMEs' environment on innovative activities is observed in an empirical study from Kalantaridis and Pheby (1999), regarding an agglomeration of manufacturing SMEs that failed to transform geographical proximity into an innovative milieu. The authors focused on the experience of Bedfordshire, a county in the UK that was characterized by its proximity to the London markets, the presence of $R \& D$ facilities, a considerable agglomeration of engineering SMEs, and the existence of two complementary universities: factors often identified in the literature as conducive to innovative activity. "However, these locational advantages failed to act as the stimulus of a cluster of 
innovative SME's, the rates of innovative activity in the locality were well below those reported elsewhere in the UK." (Kalantaridis and Pheby, 1999, p.74). ) In Ireland, in a marginal rural area extending over three counties, a group of 123 start-ups was studied. The owners were asked their opinion on the institutional setting in which they operated their enterprises (McDonagh et al., 1999). Quite often, these owners had been born in the local area and came from families which were self-employed. They acknowledged the great help received in establishing their businesses from public agencies (grants), but also underlined other important sources of assistance: attitude of local bank managers, staff commitment, etc. Yet, the main idea coming out of the analysis was the lack of an adequate local entrepreneurial culture - too few people coming forward with business ideas, or the ideas proposed being more often imitative than innovative.

\section{Factors to Measure Innovative Activities in Firms}

Measurement of innovative activities became important during the 1990s, when the role of firms in the creation of jobs appeared prominent and, together with the emergence of innovations, a topic of broad public interest. In general, statistical surveys have been producing data concerning two debatable proxies: R\&D expenditures and number of patented inventions. Eventually, employment in R\&D related activities. No unambiguous direct measure of innovation outputs exists so far. The second topic explored has been the manner in which the market structure may influence the innovative activities, and conversely, the extent to which technological change has an impact on the size distribution of firms. All scientific results in such discussion have been empirically oriented, and related to several advanced industrial countries. Very occasionally, a few studies concerned rural or lagging areas (Vaz et al., 2004). The debate invariably points out that there are considerable ambiguities and inconsistencies in the results of empirical studies directly relating $R \& D$ or patents to innovation (Acs and Audresch, 1991), even more significantly if in presence of less favoured areas.

New innovation output indicators have been defined having as reference the total number of innovations. Kleinknecht and Bain (1993) proposed several methods for collecting data: postal surveys for self-assessment by managers of their innovations or literature-based counting of innovations (in trade journals). Experiences with the first method (in Great Britain, Norway, Denmark, Germany and the Netherlands) and with the second one (in United States, the Netherlands, Ireland) helped to highlight the issues and related ways to work towards general inquiries. However, most of these methods proved to be quite subjective, making a scientific consensus difficult for the general use of the scientific community. When the Community Innovation Survey (CIS) was implemented by EUROSTAT to collect firm-level data on inputs to, and outputs of, the innovation process across a wide range of industries and across member-states and, 
occasionally, across regions, a great toll allowed many advances in the comparative analyses of innovativeness across firms, regions and nations.

In spite of its limits, the CIS is showing evidence of the actual composition of inputs engaged by the firms for implementing technological change. Their evaluation at the level of all industries shows a break-down of expenditures devoted in the EU to innovative activities: formal $R \& D$ in labs represents only $41 \%$ of the total, while product design costs account for $22 \%$, and in trials, tooling up and training there are $27 \%$. In such figures there is room for technological developments and imitations looked for in small firms.

The macro-level empirical data suggests that decision makers are correct when they conclude that firms, including the smaller ones, are job creators and engines of economic growth. However, such statements do not help to produce more scientific evidence on the precise role that firms play in the growth mechanisms. Within the context of a learning economy, all enterprises have to adapt their technology to new standards of distribution and to logistic channels, in an environment of intensifying competition, mostly to meet the requirements of consumers and public bodies. Big corporations are well organized to learn about and acquire the new inputs, using them first for the dynamics of their own innovative activities (Nonaka and Takeuchi, 1995). A different situation however, is observed for small firms, whose organization is not so developed for immaterial investments. Nevertheless, we presume that all enterprises of small size are also able to make some kind of effort to acquire the necessary knowledge to evolve with new technologies, and to adapt their production in line with the industrial and social evolution.

All categories of enterprises are considered within one industry, but they may belong to different regional or local innovation systems with which they are interacting and competing for innovative and market activities using the same tools and the same knowledge flows (Cooke et al., 1998; Lester, 2006).

In a way, inspired by Grosjean and Crevoisier (1998), it could be argued that such regional or local innovation systems result from historical, path-dependent processes, with high degrees of institutional and organizational specificities (Wright, 1997). Thus, within an industrial context, firms are embedded in a technological regime, defined by the level and type of opportunities for innovations, by the cumulation of technological knowledge, and by the means of knowledge transmission. The examination of the technological regime of an industry allows some predictability about the kind of enterprises which may innovate, because of the possibilities for protecting innovations (appropriability); the strength of a dominant design (opportunity); the nature and the continuity in the learning processes (cumulation); and the tacitness of knowledge and the means of transmission used. 
This theoretical framework suggests a set of related issues that may determine regional patterns of firms' capacity to dynamically innovate. In order to pursue the goal of detecting these patterns, we have applied our investigation to the Portuguese knowledge and innovation system, using a set of private companies and public organizations located in Portugal, evaluated by their WebPage contents. On the basis of this data set, geographically located and classified by NUTS II regions, a combination of multivariate statistical methods was employed to detect group performances and then to analyse them by their gradient of capacity to dynamically innovate. The results demonstrate that this method can provide useful information for policy evaluation of innovation systems at both the regional or national levels. An earlier publication (Vicente et al., 2010) provides further details on the sampling and variables ${ }^{5}$.

\section{Methodology}

The information used in our analysis can be organized in an $I x J$ binary data matrix $(\mathrm{Y})$ in which the $I$ rows correspond to the above-mentioned 620 units (organizations or firms), and the $J$ columns correspond to the 10 innovation attributes (listed in Footnote $5)$ scored as binary variables, viz. present or absent ( 1 or 0$)$.

As a means to obtain the main innovation gradients, of the entities and their relation to the observed characteristics, we apply a novel algorithm, recently proposed by Demey et al. (2008) that combines Principal Coordinates Analysis (PCoA) and Logistic Regression (LR) to construct an External Logistic Biplot (ELB).

The algorithm starts with a PCoA, as a technique for ordering the units, in Euclidean space, on the latent gradients. The second step of the algorithm is adjusting a logistic regression model for each variable by using the latent gradients as independent variables. Geometrically, the principal coordinates scores can be represented as points on the map and the regression coefficients are the vectors which show the directions that best predict the probability of the presence of each characteristic.

To search for the variables associated with the ordering obtained in PCoA, we look for the directions in the ordering diagram that best predict the probability of the presence of each unit. So, the second step of the algorithm is adjusting a logistic regression model for each variable by using the latent gradients as independent variables. According to the geometry of the linear biplot for binary data (VicenteVillardón et al., 2006), in which the responses along the dimensions are logistic (coined Logistic Biplots, LB), each variable is represented as a direction vector through the origin.

\footnotetext{
5 The variables used in our empirical study are: Promoting knowledge (PK); Studying process (SP); Managing (Mg); Promoting R\&D (PRD); Knowledge transfer (KT); Support to entrepreneurship (SE); New product development (NPD); Promoting partnership and cooperation (PPC); Application of external technologies (AET); Orientation (Or). The number of firms considered here is 620 .
} 
For each characteristic, the ordination diagram can next be divided into two separate areas predicting presence or absence (following our binary logic), while the two areas are separated by a line that is perpendicular to the characteristic vector in the Biplot and cuts the vector at the point predicting a 0.5 probability. The characteristics associated with the configuration are those that predict the respective presences adequately.

Measures of the quality of the representation of units, and the variables on the graphical representation, are also calculated in this framework. The quality of representation of a unit is measured as the percentage of its variability accounted for by the reduced dimension solution, and it is calculated as the squared cosine of the angle between the point/vector in multidimensional space and its projection onto the low dimensional solution. As the representation is centred at the origin, the variability of each unit is measured by its squared distance to the centre, so that the quality of representation can be measured by the ratio between the squared distance in the reduced dimension and the squared distance in the complete space.

The quality of representation of a variable can then be measured as a combination of three indexes: the p-value of the logistic regression, in order to test the relation between the solution and each variable (using the deviance); the Nagelkerke R-squared; and the percentage of correct classifications, using the value 0.5 as the cut-off point for the expected probability. As a way to identify which gradient (dimension) is most related to each variable, the cosine of the angle of the vector representing the variable and the dimension is calculated. Clearly, a variable is more related to a particular gradient when the absolute value of the cosine is higher than the cosine for other gradients.

To produce an elegant solution, we may present a Voronoi diagram of the spatial relationships; that is, a special decomposition of a metric space determined by distances to a specified discrete set of points: centroids form then a k-means cluster analysis of the ELB coordinates.

A computer program, based on Matlab code, for implementing these methods is available and can be obtained from the website: http://biplot.usal.es.

\section{Empirical Results}

A Principal Coordinates Analysis is first applied in our empirical work to the dissimilarities matrix, based on the Russel and Rao coefficient. This produced the following results (see Table 1). The inertia first principal plane (two-dimensional solutions) appears to account for 77.53 per cent of the variability. The first eigenvalue is significantly higher than the second one, meaning that, even if the two innovation gradients are considered, the first (horizontal) dimension accounts for most of the information. 
In Figure 2 (ELB map) (see also Section 5) we can observe a complex representation of the main patterns of the determinants of dynamic innovation according to the ten considered critical variables: Promoting knowledge (PK); Studying process (SP); Managing (Mg); Promoting R\&D (PRD); Knowledge transfer (KT); Support to entrepreneurship (SE); New product development (NPD); Promoting partnership and cooperation (PPC); Application of external technologies (AET); Orientation (Or). Each company profile has a particular location on the graph. The distance between any two company-points of the configuration approximates, as closely as possible, the dissimilarity between them.

The global goodness of fit as a percentage of correct classifications in this Biplot appears to be 90.43 per cent. The goodness of fit (quality of representation) indexes for each variable is shown in Table 2. All the R-squared values are higher than 0.6, and therefore all variables are closely related to the two-dimensional PCoA solution. All the indexes considered in the study are relevant in the interpretation of the gradients founded.

Table 1. Eigenvalues, percentage of accounted variance

\begin{tabular}{|r|r|r|}
\hline Eigenvalue & \% of variance & Cumulative \% \\
\hline 37.49 & 57.99 & 57.99 \\
\hline 6.78 & 10.49 & 68.49 \\
\hline 5.85 & 9.05 & 77.53 \\
\hline
\end{tabular}

Table 2. Goodness-of-fit of the variables

\begin{tabular}{|l|l|l|l|l|}
\hline Variable & Deviance & $p$-value & $R^{2}$ & \% Correct \\
\hline PT & 674.94 & $<0.0001$ & 0.88 & 93.42 \\
\hline SP & 418.70 & $<0.0001$ & 0.68 & 82.50 \\
\hline Mg & 906.68 & $<0.0001$ & 0.92 & 92.29 \\
\hline PRD & 549.93 & $<0.0001$ & 0.77 & 89.08 \\
\hline KT & 763.53 & $<0.0001$ & 0.90 & 92.67 \\
\hline SE & 267.13 & $<0.0001$ & 0.60 & 90.69 \\
\hline NPD & 723.74 & $<0.0001$ & 0.94 & 97.27 \\
\hline PPC & 733.39 & $<0.0001$ & 0.92 & 95.19 \\
\hline AET & 822.17 & $<0.0001$ & 0.93 & 95.02 \\
\hline Or & 544.62 & $<0.0001$ & 0.77 & 83.95 \\
\hline
\end{tabular}

Table 3 contains the cosines of the angles of the variables (Innovation indexes) with their dimensions (latent gradient). It should be pointed out that any direction in the two-dimensional solution, and not just the main dimensions, can be considered as an 
innovation gradient. The graph can help us to look for the most interpretable directions. An analysis of the cosines' value in the graph identifies two main directions for innovation gradients. A third column has been added to Table 3 showing which variables are most related to each direction. The first gradient is almost parallel to dimension 1 (horizontal) and the second one to dimension 2 (vertical). Although the variable 'Promoting knowledge' has a higher cosine with the first dimension, it has been assigned to the second gradient after inspecting the graph.

From the graph and the quality indexes, we can now conclude that the first innovation gradient is mainly given by a combination of the following variables: Promoting knowledge (PK); Managing (Mg); Promoting R\&D (PRD); Knowledge transfer (KT); Promoting partnership and cooperation (PPC); Orientation (Or).

Observing the directions of the vectors relative to the first latent attribute, it can be concluded that all the above-mentioned attributes tend to show up together (as we hypothesized in the Introduction). The graphical representation corroborates the interpretation of the innovation gradients in terms of their relations to the variables. It can also be concluded from the graph that there is a high correlation between Promoting knowledge, Studying processes, Managing, Promoting R\&D, Knowledge transfer and Orientation. This is because they have small angles pointing in the same direction.

Table 3. Cosines of the angles between the index and the latent gradient

\begin{tabular}{|l|l|l|l|}
\hline Variable & $1^{\text {st }}$ gradient & $2^{\text {nd }}$ gradient & Associated gradient \\
\hline PK & 0.96 & 0.28 & 1 \\
\hline $\mathrm{SP}$ & -0.87 & 0.49 & 2 \\
\hline $\mathrm{Mg}$ & -0.98 & -0.20 & 1 \\
\hline $\mathrm{PRD}$ & -0.94 & -0.35 & 1 \\
\hline $\mathrm{KT}$ & -0.96 & -0.27 & 1 \\
\hline $\mathrm{SE}$ & -0.31 & -0.95 & 2 \\
\hline NPD & -0.35 & 0.94 & 2 \\
\hline PPC & -0.75 & -0.66 & 1 \\
\hline AET & -0.40 & 0.92 & 2 \\
\hline Or & -0.95 & -0.31 & 1 \\
\hline
\end{tabular}

A Voronoi diagram of the spatial relationships is next represented in Figure 1. We are given a set of points $s$ in the plane, which are the centroids from a k-means cluster analysis onto the ELB coordinates, and which are the Voronoi sites. Each site has a Voronoi cell, consisting of all points closer to a centroid than to any other site. The segments of the Voronoi diagram are all the points in the plane that are equidistant to the two nearest sites. The Voronoi nodes are the points equidistant to three (or more) 
sites. Two points are adjacent on the convex hull if and only if their Voronoi cells share an infinitely long side.

Analysing the Voronoi diagrams and clusters, we are able to find four groups of entities with homogeneous patterns in the two gradients considered.

At national level, the institutions positioned on the left side of the graph have a higher capacity to dynamically innovate, because they tend to aggregate higher values of those variables (attributes) - this happens in Cluster 2. However, the institutions positioned on the right side of the figure lack most (or all) of such attributes - this happens in Cluster 4. As such, this measurement may be interpreted as a complex innovation index, defined here as the Gradient of Capacity to Dynamically Innovate (GCDI). Using this method, the scores of the variables on the first gradient can be ordered to obtain the sequence of attributes that define the degree of innovation. The most innovative institutions have the total number of characteristics, and they are then followed by those entities that have all of them, except Promoting R\&D (PRD) whose score is situated to the left of the graph. The next group has all the attributes related to the gradient, except Promoting R\&D and Managing (Mg), and so on.

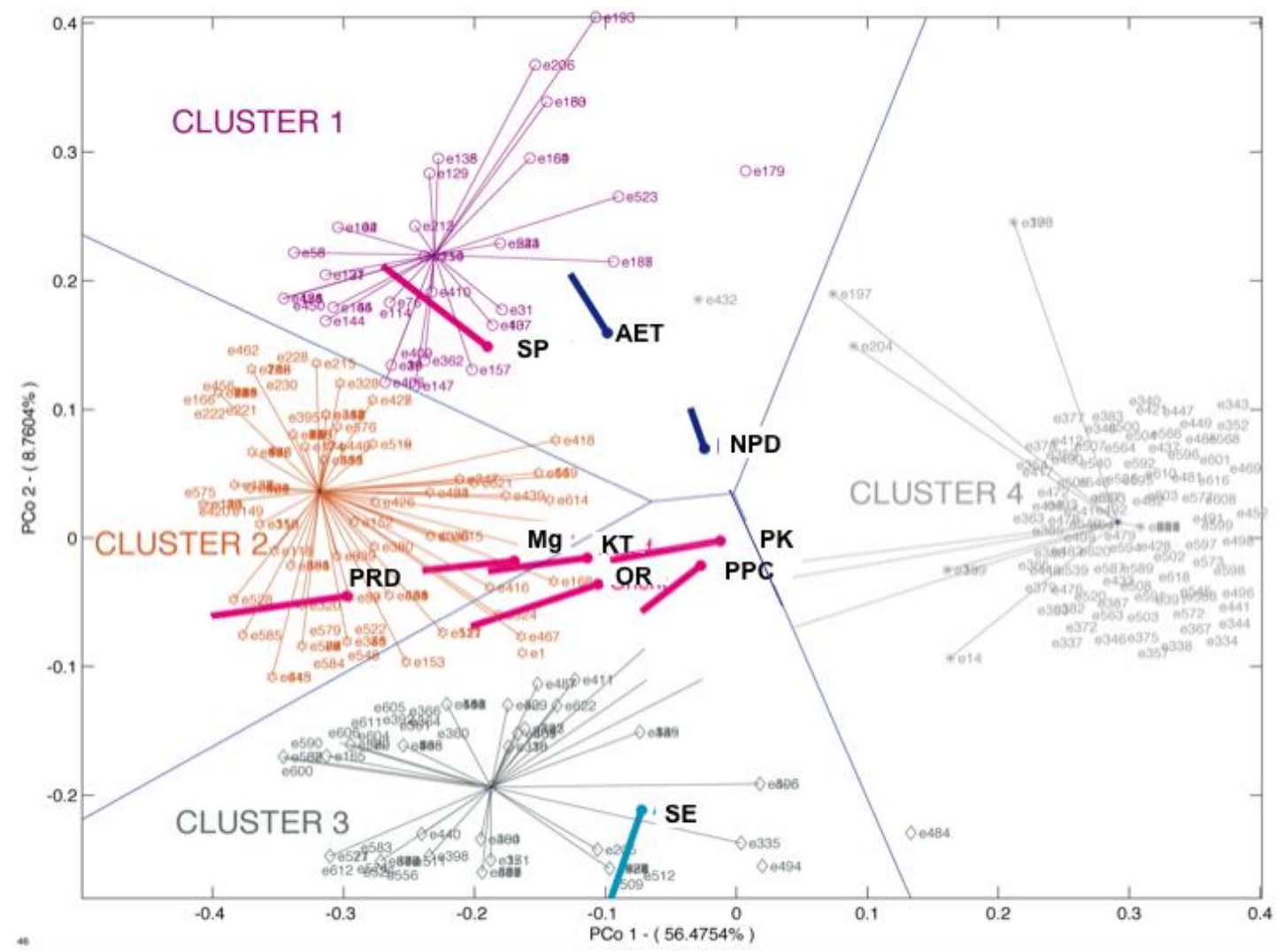

Figure 1. Voronoi diagram representation of spatial relationships and clusters

The second innovation gradient is a combination of Studying process (SP); New product development (NPD); Application of external technologies (AET) pointing in the positive direction; and Support to entrepreneurship (SE) pointing in the opposite 
direction. This secondary gradient is not correlated with the first one, and summarizes an aspect of innovation independent from the main dynamic pattern. The institutions situated on the top, Cluster 1, of the graph combine the first three above-mentioned attributes and the last is absent; while the institutions situated at the bottom, Cluster 3, have the last attribute (SE), but none of the first three above-mentioned attributes. Some profiles can already be associated with these clusters: Cluster 2, the multiple innovative profiles; Cluster 4, the non-innovative profile; while the other two clusters suggest more focused profiles.

\section{NUTS II Distributions of Clusters}

Once we have identified and represented the institution clusters on the Euclidean map containing the two innovation gradients, we then study the composition of the groups according to their geographical distribution. Table 4 shows the cross-tabulation of clusters and regions.

Table 4. Percentage of each cluster per region (cross-tabulation between clusters and regions (NUTS II))

\begin{tabular}{|l|r|r|r|r|}
\hline & \multicolumn{1}{|c|}{ Cluster 1 } & \multicolumn{1}{c|}{ Cluster 2 } & \multicolumn{1}{c|}{ Cluster 3 } & \multicolumn{1}{c|}{ Cluster 4 } \\
\hline Alentejo & 2.20 & 1.20 & 4.80 & 4.70 \\
\hline Algarve & 0.00 & 1.20 & 2.90 & 2.00 \\
\hline Centro & 13.00 & 15.00 & 14.30 & 12.50 \\
\hline Lisboa & 50.00 & 52.00 & 41.00 & 38.30 \\
\hline Norte & 30.40 & 21.40 & 27.40 & 26.40 \\
\hline Islands & 0.00 & 1.70 & 7.60 & 0.30 \\
\hline
\end{tabular}

Table 4 indicates that in Cluster 1 more than 80 per cent of the institutions belonging to that Cluster are from the Lisbon and the North NUTS II regions. This also occurs in Cluster 2, where more than 73 per cent of the institutions are from Lisbon and the North; in Cluster 3 more than 68 per cent and in Cluster 4 more than 64 per cent are from Lisbon and the North. The Centre NUTS II area is also of relative importance in all the clusters, with percentages between 13 and 15 per cent.

When analysing the distribution of clusters found in the different NUTS regions (see Table 5), we observe that in the Alentejo it is Cluster 4 that is of the greatest relevance, since it represents 63.6 per cent; i.e. most of the institutions in the Alentejo are characterized by the absence of innovation. This is also the case for the other NUTS regions, with the exception of the Islands; in all of those other regions there are high percentages of institutions lacking innovation, ranging between 42.0 and 54.5 per cent.

In the Alentejo, 36.6 per cent of the institutions have innovations, but the types of innovation vary. Most have innovations belonging to Cluster 3 (22.7 per cent); the type 
of innovation characterizing Cluster 2 appears in 9.1 per cent of the institutions and that representing Cluster 1 is only seen in 4.5 per cent of the Alentejo institutions.

In the Algarve, 46.5 per cent of the institutions have innovations but the type of innovation is different. Most have innovations belonging to Cluster 3 (27.3 per cent); the type of innovation characterizing Cluster 2 appears in 18.2 per cent of the institutions, but none of the Algarve institutions has the type of innovation characterizing Cluster 1.

Table 5. Percentage of institutions which belong to each cluster for each NUTS II region (cross-tabulation between Clusters and NUTS II regions)

\begin{tabular}{|l|r|r|r|r|}
\hline & Cluster 1 & Cluster 2 & Cluster 3 & Cluster 4 \\
\hline Alentejo & 4.5 & 9.1 & 22.7 & 63.6 \\
\hline Algarve & 0.0 & 18.2 & 27.3 & 54.5 \\
\hline Centro & 7.1 & 31.0 & 17.9 & 44.0 \\
\hline Lisboa & 8.6 & 33.5 & 16.0 & 42.0 \\
\hline Norte & 9.0 & 23.7 & 17.3 & 50.0 \\
\hline Islands & 0.0 & 25.0 & 66.7 & 8.3 \\
\hline
\end{tabular}

In the Centre, 56 per cent of the institutions have a high degree of innovation but the type of innovation is also different. Most have innovations belonging to Cluster 2 (31 per cent); the type of innovation characterizing Cluster 3 appears in 17.9 per cent of the institutions, and that representing Cluster 1 is only seen in 7.1 per cent of the institutions in the Centre.

In Lisbon, 58 per cent of the institutions have innovations, but the type of innovation is different. Most have innovations belonging to Cluster 2 (33.5 per cent); the type of innovation characterizing Cluster 3 appears in 16 per cent of the institutions, and that representing Cluster 1 is seen in 8.6 per cent of the institutions in Lisbon.

In the North, 50 per cent of the institutions have innovations, but the type of innovation is different. Most have innovations belonging to Cluster 2 (23.7 per cent); the type of innovation characterizing Cluster 3 appears in 17.3 per cent of the institutions, and that representing Cluster 1 appears in 9 per cent of the Lisbon institutions.

On the Islands, only 8.3 per cent of the institutions do not feature innovations. Most have innovations belonging to Cluster 3 (66.7 per cent), followed by Cluster 2, with 25 per cent.

The data in Tables 4 and 5 may be translated into Figure 2, which is a comparative spatial analysis of the regional profiles of firms in terms of their innovative patterns in the country. 


\section{Conclusions}

From the application of the Logistic Biplot methodology to the institutional databases on Portuguese regions we were able to demonstrate that institutions are very diverse in the way they combine determinants for their patterns in terms of the dynamics of innovation - the two-dimensional PCoA solution accounts for the main interpretation of the regional variation patterns related to the data used.
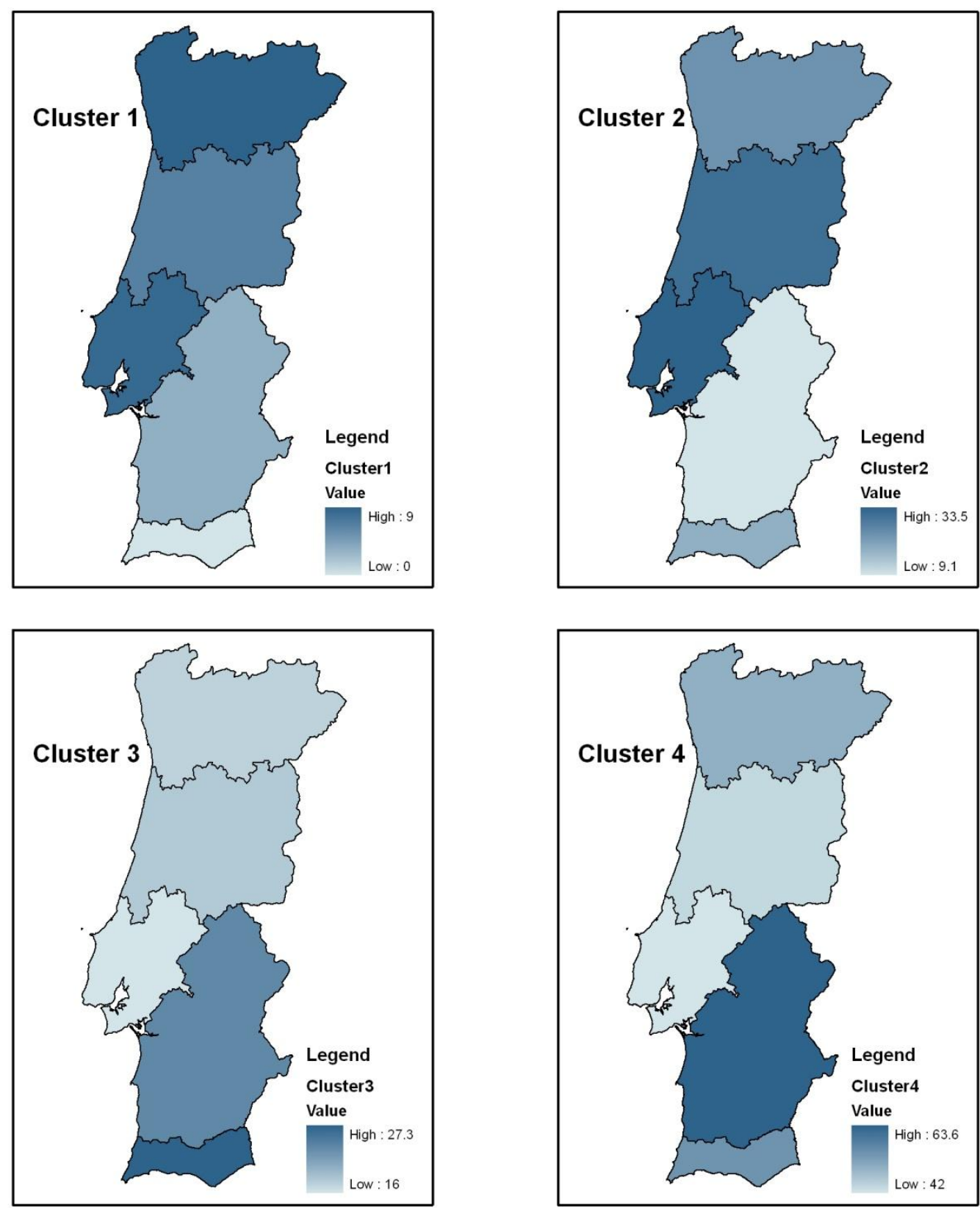

Figure 2. Comparative regional spatial analysis of the different types of innovation cluster 
Considering the relation of the variables to the innovation gradient of capacity to dynamically innovate, we are able to conclude that the determinants 'Promoting knowledge', 'Managing', 'Promoting R\&D', 'Knowledge transfer', 'Promoting partnership \& cooperation' and 'Orientation', are clearly the most influential ones.

There is no homogeneous distribution of clusters among the regions, as we expected. It appears that 80.4 per cent of the institutions with higher innovation levels (Cluster 1) is located in the Lisbon region (50 per cent) and the North region (30.4 per cent), 13 per cent is in the Centre of the Country, 2.20 per cent (just one institution) is in the Alentejo region; and there is none in the Islands or the Algarve.

Within Cluster 2, 52 per cent of the institutions are also in the Lisbon region; 21.4 per cent in the North; and 15 per cent in the Centre.

We can conclude, therefore, that the institutions possessing a higher level of innovation are concentrated in the Lisbon, Centre, and North regions.

Cluster 3, characterized by different innovation indices, has an internal distribution similar to the previous groups: most of the institutions are from the Lisbon (41 per cent), North (25.7 per cent) and Centre (14.3 per cent) regions. In this case, 7.6 per cent of the institutions are from the Islands.

Also, 38 per cent of the institutions in Cluster 4 (no innovation) are from Lisbon and 26.4 per cent are from the North. The highest percentage of non-innovative institutions are concentrated in the group Lisbon-North-Centre (Middle-North of the country).

Although Lisbon is the region with institutions which have the highest innovation level, it should be noted that of the 269 institutions in that region 42 per cent do not have any of the innovation characteristics, while 8.6 per cent have the highest innovation level. A similar situation occurs for the North and Centre regions. In the rest of the areas, the percentage of institutions without any innovation, is higher.

By identifying the specific nature of the innovative regional structure of innovative firms and public institutions in Portugal, many advantages and fragilities in the firms' capacity to cooperate may be identified and clearly interpreted; and, moreover, their cooperative patterns (networks) can be closely examined. Such a goal represents a step towards governance structures in agreement with Storper and Harrison (1991), whose impressive amount of work remained inconclusive due to lack of empirical evidence.

Moreover, the method proposed in our study is highly useful for policy makers, who need handy simulative tools to project their policy actions. In this case, on account of the geometrical visibility of the different attributes which determine the firm's capacity to innovate, it is easier to identify the exact set of actions to be taken in order to improve the specifically chosen profiles - which makes this method a suitable instrument for tailor-made policies. 


\section{Acknowledgements}

Paper financed by the following grant: PTDC/CS-GEO/102961/2008, Portuguese Science Foundation for Science and Technology (FCT).

\section{References}

ACS, Z. J. and AUDRETSCH, D. B. (1991), Innovation and Technological Change. An International Comparison. The University of Michigan Press.

ACS, Z. J. and AUDRETSCH, D. B. (1993), 'Analysing Innovation Output Indicators: the US Experience', in: Kleinknecht, A. and Bain, D. (eds), New Concepts in Innovation Output Measurements, S. Martin's Press, New York, 10-41.

ACS, Z. J. and AUDRETSCH, D. B., BRAUNERHJELM, P. and CARLSSON, B. (2004), 'The missing link: the knowledge filter and entrepreneurship in endogenous growth. CEPR Discussion Paper

AUDRETSCH, D.B., KEILBACH, M.C. and LEHMANN, E.E. (2006), 'Entrepreneurship and Economic Growth'. Oxford University Press, Oxford.

ASHEIM, B. T. and ISAKSEN, A. (2003), 'SMEs and the regional dimension of innovation', in: Ascheim et al. (eds) Regional Innovation Policy for Small-Medium Enterprises, Edward Elgar, Cheltenham, 21-46.

BELOTTI, C. (1999), 'La modernisation technologique des petites entreprises en zone rurale. Réflexions autour d'études de cas suédois', Revue Internationale PME, 12, 1 - 2, 127-150.

CAMAGNI, R. (1991), 'Introduction: from the local milieu to innovation through corporation networks', in: Camagni, R. (ed), Innovation networks: spatial perspectives, Belhaven Press, London and NewYork, 1-9.

CAMAGNI, R. (1995a), 'Espace et temps dans le concept de milieu innovateur', in: Ralllet, A. and Torre, A. (eds), Économie Industrielle et Économie Spatiale, Economica, Paris, 193-210.

CAMAGNI, R. (1995b), 'Global network and local milieu: towards a theory of economic space', in: Conti, S., Malecki, E. and Oinas, P. (eds), The Industrial Enterprise and its environment: Spatial Perspectives, Avebury, England, 195-213.

CAMAGNI, R. and MAILlAT, D. (1999), 'The Innovative Milieu Paradigm in Contempory Spatial Economy', Revue d'Économie Régionale et Urbaine, 3, 425-428.

COOKE, P., BRACZYK, H-J and HEIDENREICH, M. (eds.) (1998), Regional Innovation Systems: The Role of Governances in a Globalized World, 2nd Edition, Routledge, London.

DEMEY, J. R., VICENTE-VILLARDÓN, J. L., GALINDO, M. P. and ZAMBRANO, A.Y. (2008), 'Identifying Molecular Markers Associated with Classifications of Genotypes by External Logitic Biplot', Bioinformatics, 24, 28-32.

FAGERBERG, J. (1987), 'A technology gap approach to why growth rates differ', Research Policy, 16, 87-99.

FAGERBERG, J. (2003), 'Schumpeter and the Revival of Evolutionary Economics: an Appraisal of the Literature', Journal of Evolutionary Economics, 13, 125-59.

FISCHER, M. M. (2006), Innovation, Networks and Knowledge Spillovers, Springer, Berlin.

FREEL, M. (1998), 'Evolution, innovation and learning: evidence from case studies', Entrepreneurship \& Regional Development, 10, 2, 137-149.

VICENTE, P., NORONHA VAZ, T. and NIJKAMP, P. (2010), 'Institutional Capacity to Dynamically Innovate: An Application to the Portuguese Case', Technological Forecasting \& Social Change, accepted.

GROSJEAN, N. and CREVOISIER, O. (1998), Systemes de Production Territoriaux: vers une methode systematique d'identification et d'evaluation, Université de Neuchâtel.

HALL, R. and WEE, M. (1995), 'The Regions in a Enlarged Europe', in: Hardy, S., Hart, M., Albrechts, L. and Katos, A. (eds), An Enlarged Europe. Regions in Competition? Regional Policy and Development, 6. Jessica Kingsley Publishers and Regional Studies Association, London, 8-21.

KAISER, U. (2002), 'Measuring Knowledge Spillovers in Manufacturing and Services: An Empirical Assessment of Alternative Approaches', Research Policy, 31, 1, 125-144.

KALANTERIDIS, C. and PHEBY, J. (1999), 'Processes of innovation among manufacturing SMEs: the experience of Bedfordshire', Entrepreneurship \& Regional Development, 11, 1, 57-78. 
KALANTARIDIS, C. and KIRAT, T. and LE BAS, C. (1995), 'Apprentissage technologique et interactivité dans les systèmes localisés de production et d'innovation', in: Rallet, A., Torre, A. (eds), Économie Industrielle et Économie Spatiale. Association de Science Régionale de Langue Française, Paris, 422-443.

KEEBLE, D. (1997), 'Small Firms, Innovation and Regional Development in Britain in the 1990s', Regional Studies, 31, 3, 281-293.

KEEBLE, D. and WILKINSON, F. (1999), 'Collective Learning and Knowledge Development in the Evolution of Regional Clusters of High Technology SMEs in Europe', Regional Studies, 33, 4, 295-303.

KEEBLE, D. and WILKINSON, F. (eds.) (1999), 'Networking and Collective Learning in RegionallyClustered High-Technology SMEs in Europe', Final Report to DG XII, European Commission, University of Cambridge, ESRC Centre for Business Research, Cambridge.

KLEINKNECHT, A. and BAIN, D. (1993), New Concepts in Innovation Output Measurements, St Martin's Press, New York.

LANDABASO, M. (1997), 'The Promotion of Innovation in Regional Policy: Proposals for a Regional Innovation Strategy', Entrepreneurship \& Regional Development, 9, 1, 1-24.

LANGLOIS, R. N. and ROBERTSON, P. L. (1995), Firms, Markets and Economic Change, Routledge, London \& New York.

LESTER, R. (2006), 'Prospects for Local Innovation Systems', Paper presented at a seminar held in September 2006 at the Department of Economics, National University of Ireland, Galway.

MCDONAGH, P. (1999), 'Supporting Entrepreneurship in Marginal Rural Areas: Experience from the West of Ireland', in: Byron, R. and Hutson, J. (eds), Local Enterprise on the North Atlantic Margin, Ashgate, England and USA, 15-43.

NIJKAMP, P. (2009), 'Regional Development as Self-Organized Converging Growth', in: Kochendorfer, G., and Pleskovic, B. (eds.), Spatial Disparities and Development Policy, The World Bank, Washington DC, 205-282.

NONAKA, I. and TAKEUCHI, H. (1995), The Knowledge-Creating Company, Oxford University Press, New York \& Oxford.

OECD Territorial Review - Portugal 2008, OECD.

STORPER, M. and HARRISON, B. (1991), 'Flexibility, hierarchy and regional development: the changing structure of industrial production systems and their forms of governace in the 1990s', Research Policy, 20, 407-422.

STOUGH, R. AND NIJKAMP, P. (2009), 'Knowledge spillovers, entrepreneurship and economic development', Annals of Regional Science, 43: 835-838, Springer.

STOUGH, R., NIJKAMP, P. and VAZ, M. T. N. (eds.) (2007), Local Knowledge and Innovation Policy in Government and Policy, Special Issue of Environment and Planning C, 25(5).

TEIGLAND, R. and SCHENKEL, A. (2006), 'Exploring the Role of Communities of Practice in Regional Innovation Systems', in: Coakes, E. and Clarke, S. (eds.) The Encyclopaedia of Communities of Practice. In Information and Knowledge Management, Hersley, Idea Group.

VAZ, M. T. N. (2004), 'The environmental context for small firms in the EU', in: Vaz et al (eds) Innovation in Small Firms and Dynamics of Local Development, 13-31.

VICENTE, P., NORONHA VAZ, T. and NIJKAMP, P. (2010), 'Institutional Capacity to Dynamically Innovate: An Application to the Portuguese Case', Technological Forecasting \& Social Change, forthcoming.

VICENTE-VILLARDÓN, J. L., GALINDO-VILLARDON, M. P. and BLAZQUEZ-ZABALLOS, A. (2006), 'Logistic Biplots', in: Greenacre, M. and Blasius, J. (eds.), Multiple Correspondence Analysis and Related Methods. Boca, Raton, FL: Chapman Hall, 503-521.

WIG, H. and WOOD, M. (1997), 'What comprises a regional system of innovation?', Regional Policy and Development, 18, 66-98.

WRIGHT, G. (1997), 'Towards a more historical approach to technological change', The Economic Journal, 107, 1560-1566.

\section{Websites}

Community Innovation Survey (CIS), http://epp.eurostat.ec.europa.eu/cache/ITY_OFFPUB/KS-EM-08-001/EN/KS-EM-08-001-EN.PDF

Strategies for Collective Efficiency (2009), (http://www.pofc.qren.pt/PresentationLayer/conteudo.aspx?menuid=457) http://biplot.usal.es). 